\title{
Perancangan Sistem Informasi Geografis Penyelenggara Pernikahan di Kabupaten Karawang
}

\author{
Darmansyah $^{1}$, M. Wahidin ${ }^{2}$, Novi Apriani ${ }^{3}$ \\ ${ }^{1,3}$ Teknik Informatika, STMIK Rosma, Karawang \\ ${ }^{2}$ Sistem Informasi, STMIK Rosma, Karawang \\ E-mail: darmansyah@rosma.ac.id
}

\begin{abstract}
Wedding organizers are private services whose work helps brides-to-be. Family planning and supervising the implementation of a series of wedding events according to a predetermined schedule and budget. In the midst of busyness in preparing a perfect appearance for the bride and groom, it is almost impossible for the bride and groom to check for themselves the readiness of party supplies such as decorations, catering, and others. Therefore we need an application to help brides and grooms in facing wedding preparations, by providing a system application to get information on wedding organizers and other wedding equipment by mobile. The research method used to design this system is the System Development Life Cycle (SDLC) waterfall. The Geographic Information System for wedding organizers in Karawang district is designed to make it easier for seekers of wedding organizers to find the location of the owner of the wedding organizer and make it easier for seekers to find information about wedding organizers. This system was created so that seekers of wedding organizers can save time in preparing for a wedding and can find a location closer to the house of the bride and groom, besides making it easier to find wedding organizers that match expectations, can find out prices and make bookings or COD (Cash On Delivery).
\end{abstract}

Keywords: Information System, Wedding Organizer, SDLC, Waterfall

\begin{abstract}
Abstrak
Penyelenggara pernikahan adalah layanan pribadi yang dioperasikan karyanya membantu calon pengantin. Keluarga berencana dan mengawasi pelaksanaan acara rangkaian pesta pernikahan sesuai jadwal dan anggaran yang telah ditetapkan. Di tengah kesibukan dalam mempersiapkan penampilan diri secara sempurna bagi calon pengantin, hampir tidak mungkin bagi calon pengantin untuk memeriksa sendiri kesiapan perlengkapan pesta seperti dekorasi, catering, dan lain-lain. Oleh sebab itu di butuhkan suatu aplikasi untuk membantu calon pengantin dalam menghadapi persiapan pernikahan, dengan menyediakan sebuah aplikasi sistem untuk mendapatkan informasi penyelenggara pernikahan dan perlengkapan pernikahan lainnya secara mobile. Metode penelitian yang digunakan untuk merancang sistem ini adalah System Development Life Cycle (SDLC) waterfall. Sistem informasi geografis penyelenggara pernikahan di kabupaten Karawang dirancang agar dapat memudahkan pencari penyelenggara pernikahan dalam mencari lokasi pemilik penyelenggara pernikahan dan memudahkan pencari dalam mencari informasi tentang penyelenggara pernikahan. Sistem ini dibuat agar pencari penyelenggara pernikahan dapat menghemat waktu dalam mempersiapkan pernikahan dan dapat mencari lokasi yang lebih dekat dengan rumah calon pengantin, selain itu memudahkan dalam mencari penyelenggara pernikahan yang sesuai harapan, dapat mengetahui harga dan melakukan booking ataupun COD (Cash On Delivery).
\end{abstract}

Kata Kunci: Penyelenggara Pernikahan, Sistem Informasi, SDLC Waterfall

Article History :

Accepted 18, April, 2022

Jurnal Interkom: Jurnal Publikasi Ilmiah Bidang Teknologi Informasi dan Komunikasi

Volume 17 Nomor 01 Bulan April - Tahun 2022 


\author{
Corresponding Author: \\ Nama Penulis, Darmansyah \\ Departemen, Teknik Informatika \\ Instansi, STMIK Rosma \\ Alamat. Jl. Kertabumi No. 62 Karawang \\ Email Penulis. darmansyah@ rosma.ac.id
}

\section{Pendahuluan}

Sistem informasi geografis yang dalam bahasa inggris dapat disebut Geographic Information System (GIS) adalah sistem informasi yang memiliki keunikan yaitu mengelola dan memproses data spasial (keruangan), atau dalam artian lain yaitu sistem yang memiliki struktur yang dapat untuk membuat, menyimpan, mengelola serta dapat menyajikan informasi dalam bentuk peta geografis, seperti data koordinat lokasi suatu tempat, yang dapat disimpan pada database.[1]

Pernikahan menurut Stephens (Syakbani, 2008) adalah persatuan secara seksual yang diakui secara sosial, diawali dengan sebuah perayaan atau pemberitahuan kepada khayalak umum serta adanya perjanjian eksplisit dan bersifat permanen. Selain itu pernikahan memberi pengesahan secara sosial tentang hak asuh anak. Wingjodipoero (Evalina, 2007) mendefinisikan pernikahan sebagai suatu peristiwa yang sangat penting dalam kehidupan masyarakat, sebab pernikahan tidak hanya menyangkut mempelai wanita dan pria saja, tetapi juga menyangkut keluarga kedua mempelai. Adapun pengertian pernikahan menurut Dariyo (2004) merupakan ikatan kudus (suci atau sakral) antara pasangan dari seorang lak-laki dan seorang wanita yang telah menginjak atau dianggap telah memiliki umur cukup dewasa.[2]

Pernikahan adalah semua impian calon pengantin. bahkan termasuk kategori ibadah bagi beberapa ajaran agama. banyak calon pengantin memimpikan pernikahan mereka berkesan, istimwa, sakral serta berjalan lancar dan sukses. Namun begitu, banyak sekali persiapan yang harus dipersiapkan, seperti misalnya: lokasi/gedung akad nikah, lokasi/gedung resepsi, katering hidangan, rias pengantin dan para anggota pengiring, dekorasi pengantin, paket foto pra/pasca wedding, bahkan sampai urusan sovenir. Segala persiapan tersebut diatas seringkali menjadi kekhawatiran tersendiri oleh pihak calon pengantin. Bahkan sangat menguras tenaga, pikiran, waktu dan biaya untuk memikirkan semua persiapan tersebut. Ditambah dengan minimnya pengalaman calon pengantin akan menambah sederetan permasalahan baru.[3]

Penyelenggara Pernikahan adalah Layanan Pribadi yang Dioperasikan Karyanya membantu Calon pengantin. Keluarga Berencana dan mengawasi pelaksanaan acara rangkaian pesta pernikahan sesuai jadwal dan anggaran yang telah ditetapkan.[4]

Saat ini memang banyak sekali penyelenggara pernikahan yang berbasis sistem informasi, yang dapat memudahkan calon pengantin untuk mendapatkan informasi terkait wedding organizer yang akan di pilih untuk membantu pelaksanaan pernikahan. Namun di tengah kesibukan dalam mempersiapkan penampilan diri secara sempurna bagi calon pengantin, hampir tidak mungkin bagi calon pengantin untuk memeriksa sendiri kesiapan perlengkapan pesta seperti dekorasi, catering, dan lain-lain.

Banyaknya sistem web di Karawang untuk mencari wedding organizer, namun sulit untuk mengetahui letak geografis yang dekat dengan tempat atau rumah dari calon pengantin tersebut. Dikerenakan belum 
adanya sistem informasi geografis wedding organizer di Kabupten Karawang, maka peneliti tertarik untuk kerancangan sistem informasi geografis penyelenggara pernikahan dengan tujuan agar dapat memudahkan calon pengantin dalam mempersiapkan pernikahan serta menemukan wedding organizer sesuai dengan yang diharapkan dengan mudah dan sesuai dengan letak geografis calon pengantin.

\section{Tinjauan Pustaka}

\subsection{Sistem}

Sistem berasal dari bahasa yunani, yaitu systema yang artinya himpunan bagian atau komponen yang saling berhubungan secara teratur dan merupakan suatu keseluruhan [5].

Menurut Abdul Kadir [6] sistem adalah sekelompok elemen-elemen yang saling terintegrasi dengan maksud dan tujuan yang sama untuk melaksanakan sasaran yang telah ditentukan.

\subsection{Informasi}

Menurut Jogiyanto (2005) [7] informasi adalah data yang diolah menjadi bentuk yang lebih berguna dan lebih berarti bagi yang menerimanya.

Sedangkan menurut Abdul Kadir (2003) Informasi adalah data yang telah diolah menjadi sebuah bentuk yang berarti bagi penerimanya dan bermanfaat dalam pengambilan keputusan saat ini atau saat mendatang [8].

\subsection{Sistem Informasi Geografis}

Sistem Informasi Geografis (SIG) adalah sistem berbasis komputer yang digunakan untuk menyimpan,memanipulasi, dan menganalisis informasi geografi, Sistem Informasi Geografis (SIG) adalah kumpulan yang terorganisir dari perangkat keras komputer, perangkat lunak, data geografi, dan data personel yang didesain untuk memperoleh, menyimpan, memperbaiki, memanipulasi, menganalisa, dan menampilkan semua bentuk informasi yang bereferensi geografi [9].

\subsection{Wedding Organizer}

Wedding Organizer adalah suatu jasa khusus yang membantu calon pengantin \& keluarga dalam perencanaan dan supervisi pelaksanaan rangkaian acara pesta pernikahan sesuai dengan jadwal yang telah ditetapkan [10][11]. Berbagai strategi yang dilakukan oleh berbagai jasa Wedding Organizer diantaranya adalah servis yang diberikan kepada pelanggannya, adapula Wedding Organizer yang menyesuaikan budget (biaya) dan menyesuaikan apa yang diinginkan client [12].

\subsection{Web}

World Wide Web (WWW) lebih dikenal dengan web merupakan salah satu layanan yang didapat oleh pemakai komputer yang terhubung ke internet [12]. Web pada awalnya adalah ruang informasi dalam internet dengan menggunakan teknologi hypertext, pemakai dituntun untuk menemukan informasi dengan mengikuti link yang disediakan dalam dokumen web yang ditampilkan dalam web browser [13]. Web adalah salah satu aplikasi yang berisi dokumen-dokumen multimedia (text, gambar, suara, animasi, video) didalamnya yang menggunakan protokol HTTP (Hypertext Transfer Protocol) dan untuk mengaksesnya menggunakan perangkat lunak yang disebut browser. Web dapat diartikan sebagai sistem layanan informasi di internet yang berbasis grafis dan di dasarkan pada konteks hypertext. Hypertext sendiri tak berbeda dengan teks pada umumnya namun hypertext memiliki aturan untuk penulisan agar bisa menjadi sebuah web dan memungkinkan untuk link pada dokumen itu sendiri atau dokumen lain [14]. 


\section{Metode Penelitian}

Metode pengembangan sistem pada penelitian ini adalah metode waterfall. Model SDLC air terjun (waterfall) sering juga disebut model sekuensial linier (sequential linier). Menurut Rosa dan Shalahuddin (2011:27) Model air terjun menyediakan pendekatan alur hidup perangkat lunak secara sekuensial atau urut dimulai dari analisis, desain, pengkodean, pengujian dan tahap support [15]. Berikut adalah gambar model air terjun :

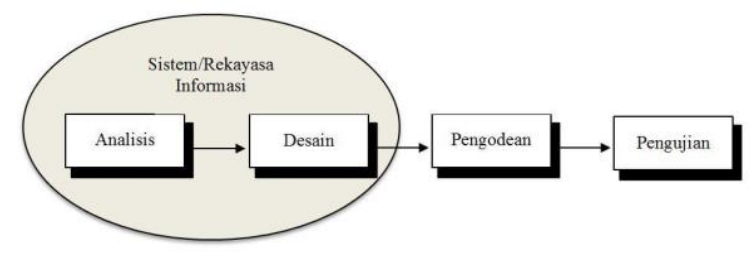

Gambar 1. Ilustrasi Model Waterfall Sumber: Rosa dan Shalahuddin (2011:27) [15]

Fase-fase model waterfall menurut Rosa dan Shalahuddin (2011:27) [15]:

a. Analisis

Analisis sistem dilakukan untuk mengidentifikasikan dan mengevaluasi permasalahan-permasalahan,

hambatanhambatan yang terjadi dan kebutuhankebutuhan yang diharapkan sehingga dapat diusulkan perbaikanperbaikan. Proses pengumpulan kebutuhan dilakukan secara intensif untuk memilah kebutuhan perangkat lunak agar dapat dipahami perangkat lunak seperti apa yang dibutuhkan oleh user. Spesifikasi kebutuhan perangkat lunak pada tahap ini perlu untuk didokumentasikan.

b. Desain

Desain perangkat lunak adalah proses multi langkah yang fokus pada desain pembuatan program perangkat lunak termasuk struktur data, arsitektur perangkat lunak, representasi antarmuka, dan prosedur pengkodean. Tahap ini mentranslasi kebutuhan perangkat lunak dari tahap analisis kebutuhan ke representasi desain agar dapat diimplementasikan menjadi program pada tahap selanjutnya.

c. Pengkodean

Desain harus ditranslasikan ke dalam program perangkat lunak. Hasil dari tahap ini adalah program komputer sesuai dengan desain yang telah dibuat pada tahap desain.

d. Pengujian

Pengujian fokus pada perangkat lunak secara dari segi logik dan fungsional dan memastikan bahwa semua bagian sudah diuji. Hal ini dilakukan untuk meminimalisir kesalahan (error) dan memastikan keluaran yang dihasilkan sesuai dengan yang diinginkan. Pengujian fokus pada perangkat lunak secara dari segi logik dan fungsional dan memastikan bahwa semua bagian sudah diuji. Hal ini dilakukan untuk meminimalisir kesalahan (error) dan memastikan keluaran yang dihasilkan sesuai dengan yang diinginkan.

\section{Hasil dan Pembahasan}

\subsection{Analisis Kebutuhan Sistem}

Analisis kebutuhan sistem dilakukan untuk mendapatkan pemahaman secara keseluruhan mengenai aplikasi yang akan dibuat agar sesuai dengan kebutuhan pengguna. Analisis kebutuhan sistem dibagi menjadi dua yaitu kebutuhan fungsional dan kebutuhan non fungsional.

\section{a. Kebutuhan Fungsional}

Kebutuhan fungsional berisi prosesproses apa saja yang nantinya dilakukan atau dikerjakan oleh sistem. Dibutuhkan sebuah sistem yang mampu melakukan fungsifungsi berikut ini : 
1) Sistem dapat menampilkan informasi wedding organizer

2) Sistem dapat menampilkan lokasi wedding organizer dengan memanfaatkan google maps

3) User dapat melakukan pemesanan fasilitas wedding organizer melalui sistem.

\section{b. Kebutuhan Non-fungsional}

Menggambarkan kebutuhan dalam aplikasi yang menitikberatkan pada properti perilaku yang dimiliki oleh sistem, diantaranya :

1) Kebutuhan Perangkat keras yang digunakan dalam pembangunan aplikasi e-marketplace wedding organizer:

Laptop dengan spesifikasi : Processor AMD E2-9000e RADEON,R2 4 COMPUTE CORES $2 \mathrm{C}+2 \mathrm{G} 1.5 \mathrm{Ghz}$ RAM 4,00 GB

2) Kebutuhan Perangkat lunak (software) yang digunakan dalam membangun aplikasi adalah sebagai berikut :

- Windows 10 digunakan sebagai sistem operasi.

- XAMPP digunakan sebagai web server.

- YED digunakan untuk mendesain UML.

- Sublime Text digunakan sebagai text editor untuk membuat aplikasi website.

\subsection{Analisis Permasalahan}

\section{a. Halaman Register dan Login}

Akses awal untuk dapat mengakses website ini user diharuskan untuk terdaftar sebagai member. Jika user belum memiliki akun, maka user harus mendaftar terlebih dahulu, namun jika user telah memiliki akun maka user dapat langsung login dengan username dan password yang dimasukan pada saat mendaftar akun.

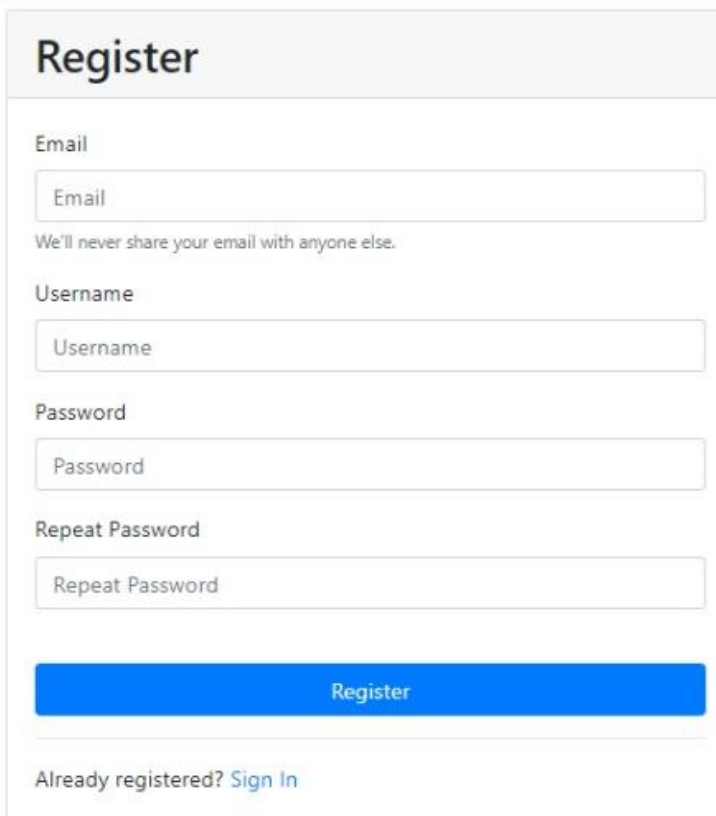

Gambar 2. Halaman Register

\section{Login}

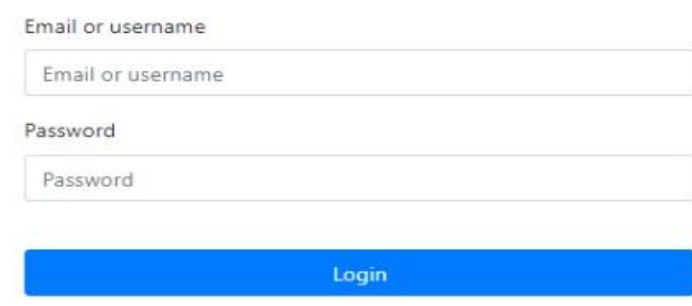

Need an account?

Gambar 3. Halaman Login

\section{b. Halaman Utama Website}

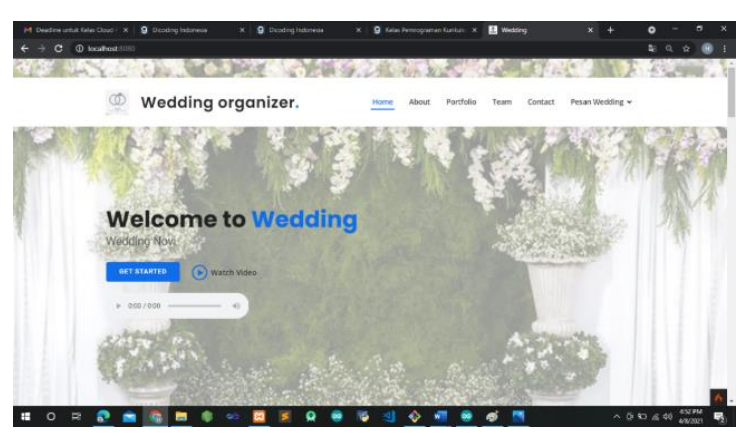

Gambar 4. Halaman Utama Website 
Pada halaman utama terdapat beberapa menu diantaranya home, about, portfolio, team, pesan wedding.

\section{c. Halaman About}

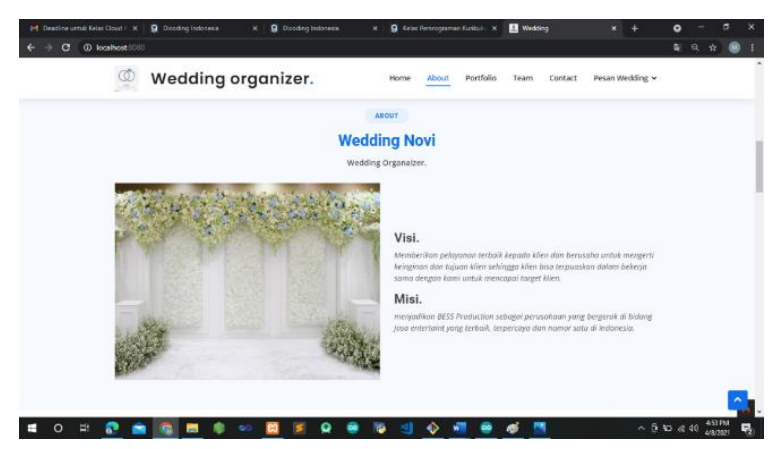

Gambar 5. Halaman About

Halaman about menampilkan tentang wedding organizer yaitu visi dan misi dari sistem yang dibuat.

\section{d. Halaman Portfolio}

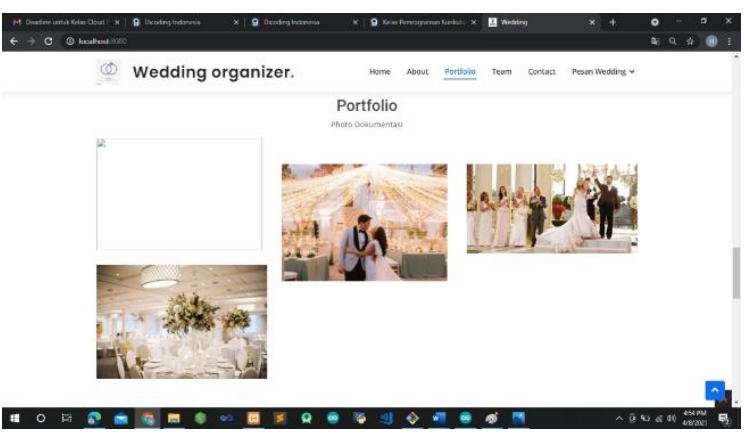

Gambar 6. Halaman Portofolio

Menampilkan halaman yang berisikan foto dokumentasi wedding organizer.

\section{e. Halaman Team}

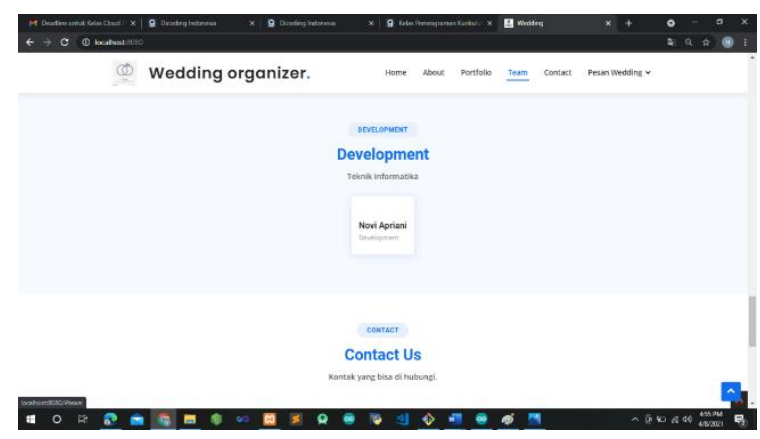

Gambar 7. Halaman Team
Pada halama ini menampilan nama development dan kontak yang bisa dihubungi.

\section{f. Halaman Maps}

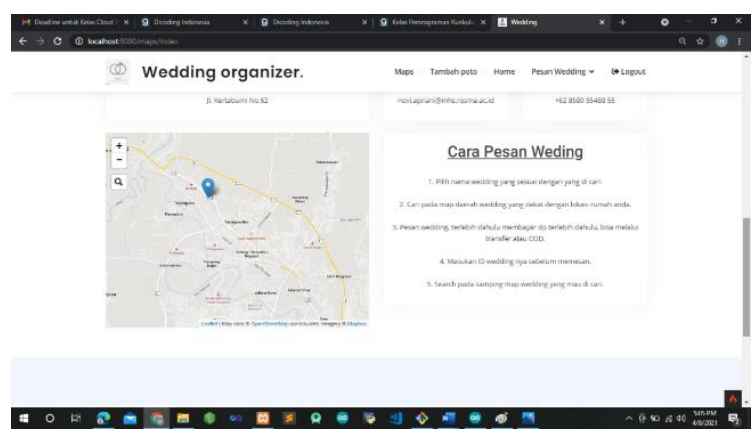

Gambar 8. Halaman Maps

Pada halaman ini menampilkan maps yang berisikan alamat pemilik wedding organizer yang sudah terdaftar.

\section{g. Halaman Pesan Wedding Organizer}

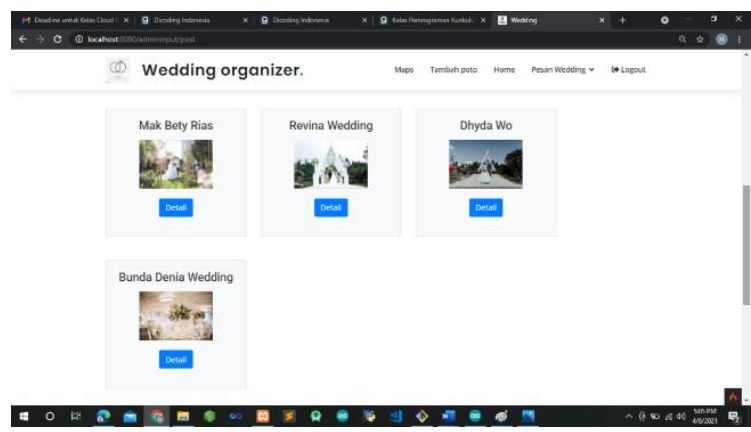

Gambar 9. Halaman Pesan Wedding

Pada halaman pesan wedding menampilkan nama-nama pemilik wedding organizer.

\section{h. Halaman Button Detail}

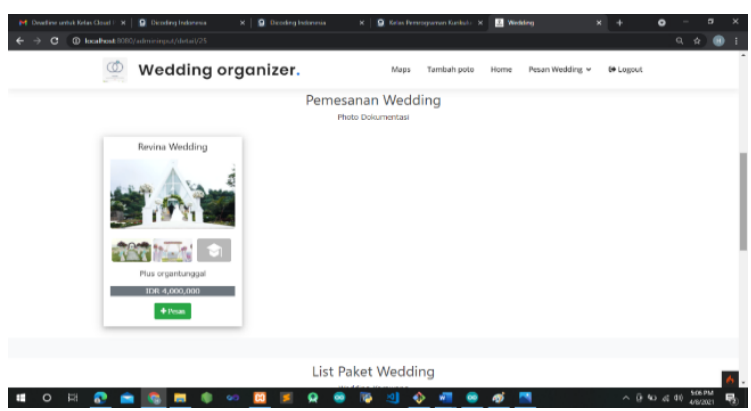

Gambar 10. Halaman Button Detail

Jurnal Interkom: Jurnal Publikasi Ilmiah Bidang Teknologi Informasi dan Komunikasi

Volume 17 Nomor 01 Bulan April - Tahun 2022 
Halaman button detail ini terdapat tampilan paket wedding organizer yang dimiliki oleh jasa wedding organizer tersebut. Setelah pencari wedding sudah menemukan paket sesuai yang diharapkan lalu dapat meng-klik button pesan pada halaman pemesanan wedding tersebut.

\section{i. Halaman Pesan Wedding Organizer}

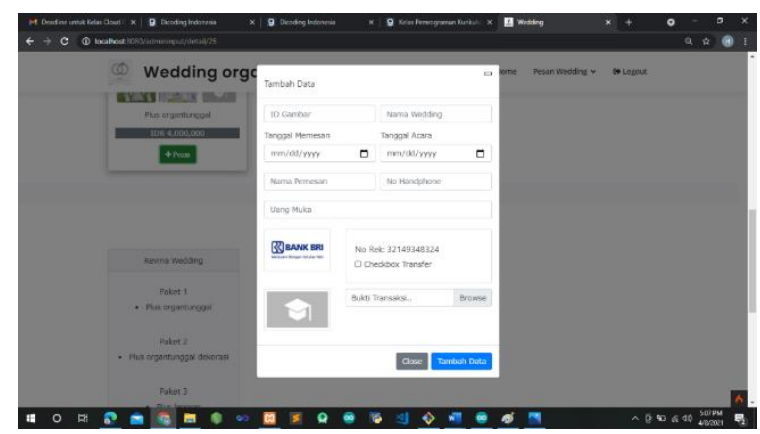

Gambar 11. Halaman Pesan Wedding Organizer

Halaman ini menampilkan pop up (ID Gambar, Nama Wedding, Tanggal Memesan, Tanggal Acara, Nama pemesan, No Handphone, Uang Muka jika akan langsung membooking wedding organizer tersebut, lalu ketika sudah transfer ke nomer rekening yang sudah tersedia pemesan mengupload bukti transfer setelah itu klik button tambah data, jika tidak close).

\section{j. Halaman Daftar Order}

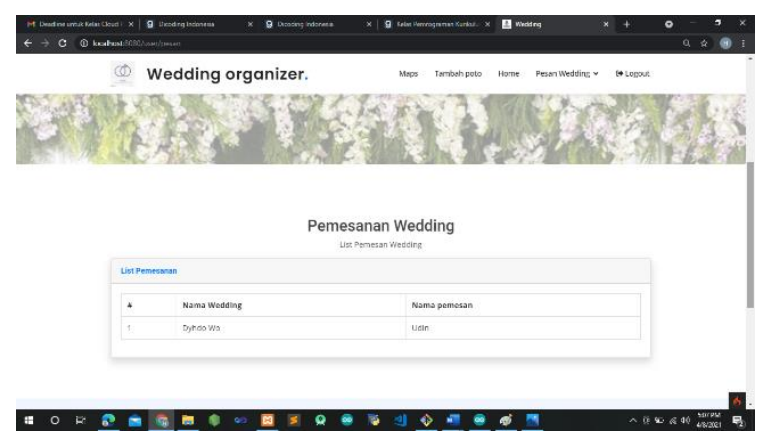

Gambar 12. Halaman Daftar Order

Pada halaman daftar order terdapat nama wedding yang sudah di booking oleh pemesan dan nama pemesan yang sudah membooking paket wedding organizer tersebut.

\section{k. Tampilan Halaman Tambah Gambar}

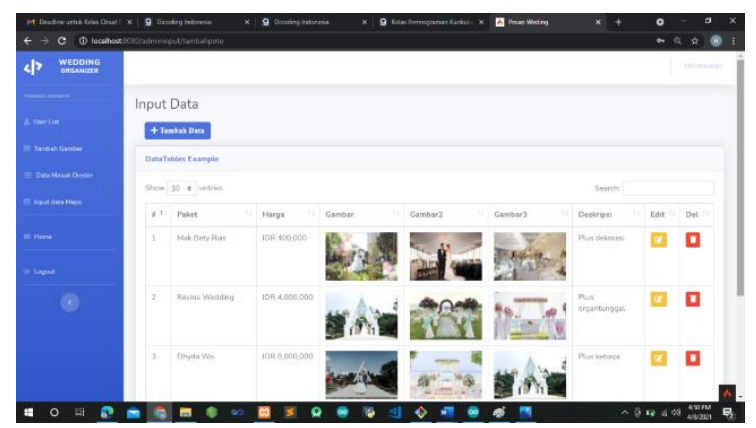

Gambar 13. Tampilan Halaman Tambah Gambar

Pada halaman tambah gambar menampilkan data dari pemilik wedding organizer, dan menampilkan edit dan delete.

\section{l. Halaman Tambah Data Wedding Organizer}

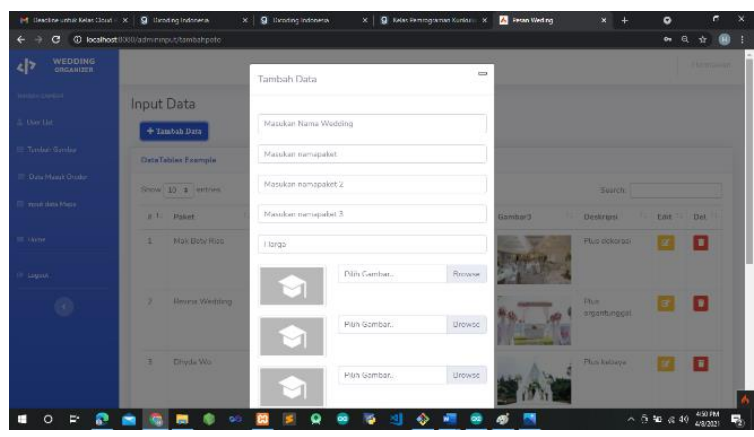

Gambar 14. Halaman Tambah Data Wedding Organizer

Halaman data wedding organizer adalah halaman untuk menambahkan data wedding organizer, dengan mengisi nama pemilik wedding, menambahkan harga wedding organizer sesuai pasaran, menambahkan gambar dokumentasi pemilik wedding organizer.

Button input data pada halaman tambah data yaitu menampilkan pop up (Masukan nama wedding, masukan nama paket yang terdapat pada pemilik wedding missal terdapat 3 paket, harga, dan pilih gambar 
photo dokumentasi dari pemilik wedding organizer). Mengisi deskripsi dan masukan, setelah data sudah lengkap dan benar admin dapat menambahkan data tersebut dengan klik button tambah data.

\section{m. Tampilan Button Edit Data}

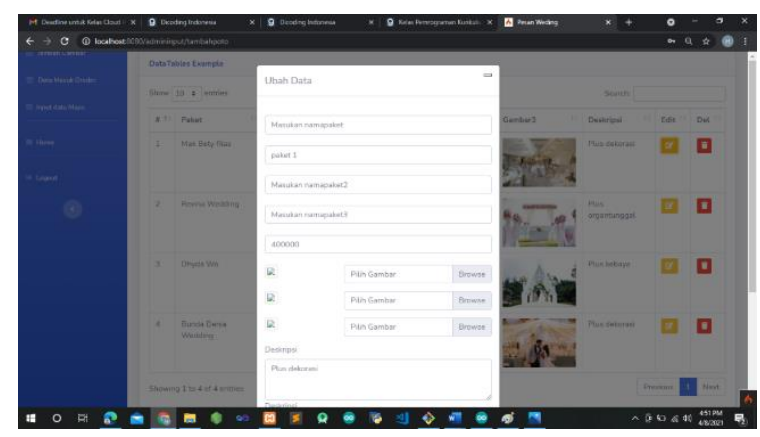

Gambar 15. Tampilan Button Edit Data

Pada tampilan button edit data terdapat pop up (masukan nama paket 1, paket 2, paket 3, harga, edit gambar, ubah deskripsi) lalu setelah selesai diubah terdapat tampilan button simpan.

\section{n. Tampilan Halaman Button Hapus}

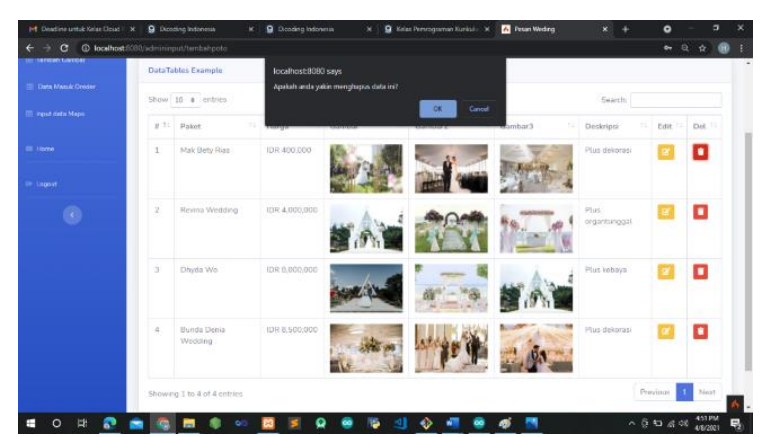

Gambar 16. Tampilan Halaman Button Hapus

Halaman button hapus menampilkan apakah anda yakin menghapus data ini? Setelah akan menghapus maka klik OK, jika tidak akan dihapus klik cancel.

\section{o. Tampilan Data Masuk Order}

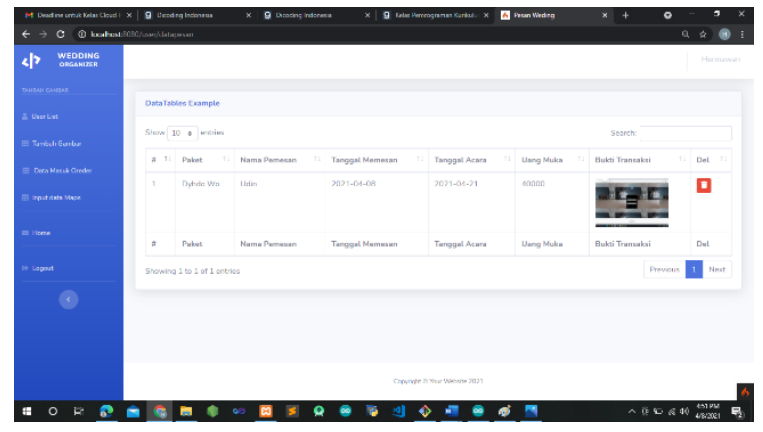

Gambar 17. Tampilan Data Masuk Order

Pada halaman ini menampilkan pemesan yang sudah menambahkan pesanan paket wedding organizer.

\section{p. Tampilan Halaman Input Data Maps}

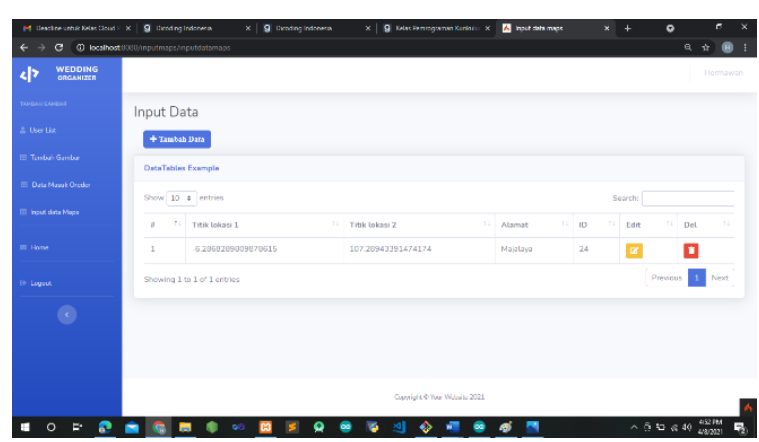

Gambar 18. Tampilan Halaman Input Data Maps

Halaman ini terdapat alamat wedding organizer yang sudah terdaftar, dan terdapat button edit, delete.

\section{q. Tampilan Halaman Ubah Data}

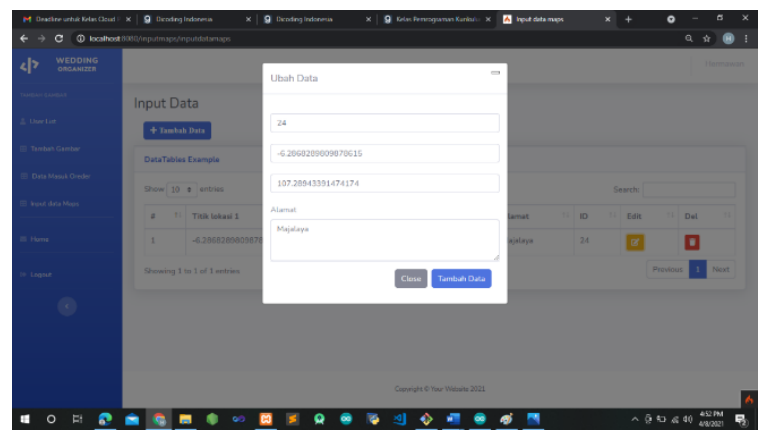

Gambar 19. Tampilan Halaman Ubah Data 
Pada tampilan ini terdapat pop up (ID, titik lokasi 1, titik lokasi 2, alamat, close dan button tambah data).

\section{Kesimpulan}

Berdasarkan penelitian yang telah dilakukan oleh penulis dalam pencapaian sistem informasi geografis penyelenggara pernikaha di kabupaten Karawang maka dapat diambil beberapa kesimpulan:

a. Sistem informasi geografis

penyelenggara pernikahan di kabupaten

Karawang dapat membantu pengguna untuk melakukan pencarian informasi wedding organizer di Kabupaten Karawang secara mudah.

b. Sistem informasi geografis penyelenggara pernikahan di kabupaten Karawang dapat membantu untuk mempermudah pemilik wedding organizer dalam memasarkan jasa wedding organizer yang dimilki.

\section{Daftar Pustaka}

[1] R. Renaldi and D. A. Anggoro, "Sistem Informasi Geografis Pemetaan Sekolah Menengah Atas/Sederajat di Kota Surakarta menggunakan Leaflet Javascript Library berbasis Website," Emit. J. Tek. Elektro, vol. 20, no. 02, pp. 123 130, 2020, doi: 10.23917/emitor.v20i02.10945.

[2] U. B. Malang, "Kepuasan pernikahan suami yang memiliki istri berkarir," pp. 1-19.

[3] P. M. Kusumantara, M. Kustyani, and T. Ayu, "Pendukung Keputusan Pemilihan Wedding Organizer Di," Tek. Eng. Sains J., vol. 3, no. I, pp. 19-24, 2019.

[4] S. M. Sari et al., "Perancangan Sistem Informasi Berbasis Web Pada Wedding Organizer Kurnia Jambi," $J$. Ilm. Mhs. Tek. Inform., vol. 2, no. 1, pp. 82-95, 2020.

[5] A. Sidik, A. R. Mariana, and A. R.
Anggraeny, "Perancangan Sistem Informasi E-Recruitment Guru Studi Kasus di SMK Kusuma Bangsa," Sisfotek Glob., vol. 8, no. 1, pp. 6974, 2018.

[6] H. Antonio and N. Safriadi, "Rancang Bangun Sistem Informasi Administrasi Informatika ( SI-ADIF )," vol. 4, no. 2, pp. 12-15, 2012.

[7] S. Mauluddin and N. Santini, "Sistem Informasi Persediaan Dan Penjualan Barang Berbasis Desktop Di D-Net House," in Prosiding Seminar Nasional Teknik, Komputer dan Rekayasa (SAINTIKS), 2018.

[8] N. Oktaviani, I. M. Widarta, and Nurlaily, "Sistem Informasi Inventaris Barang Berbasis Web Pada Smp Negeri 1 Buer," J. JINTEKS, vol. 1, no. 2, pp. 160-168, 2019.

[9] A. Anwari and M. Makruf, "Pemetaan Wilayah Rawan Bahaya Banjir Di Kabupaten Pamekasan Berbasis Sistem Informasi Geografis (Sig)," Netw. Eng. Res. Oper., vol. 4, no. 2, pp. 117-123, 2019, doi: 10.21107/nero.v4i2.127.

[10] M. Aman and Suroso, "Pengembangan Sistem Informasi Wedding Organizer Menggunakan Pendekatan Sistem Berorientasi Objek Pada CV Pesta," J. Janitra Inform. dan Sist. Inf., vol. 1, no. 1, pp. 47-60, 2021, doi: 10.25008/janitra.v1i1.119.

[11] F. Ayu and N. Fitri, "Perancangan Sistem Informasi Pemesanan Wedding Organizer Online," J. IntraTech, vol. 3, no. 2, pp. 92-104, 2019.

[12] Santoso and L. F. Adrianto, "Rancang Bangun Aplikasi Wedding Organizer Bandung Online," J. Tek. Inform., vol. 13, no. 1, pp. 43-47, 2021.

[13] A. Mubarok et al., "Sistem Informasi Pelayanan Online di Mapolresta Bandung," J. Abdimas BSI, vol. 1, no. 1, pp. 1-6, 2018.

[14] D. M. Informatika, F. Teknik, and U.

Jurnal Interkom: Jurnal Publikasi Ilmiah Bidang Teknologi Informasi dan Komunikasi 
N. Surabaya,

BANGUN

"RANCANG

KEPENDUDUKAN BERBASIS

WEB DI DESA KEDUNGREJO

WARU-SIDOARJO Efy Widyawati
Ari Kurniawan."

[15] R. A.S and M. Salahuddin, Modul Pembelajaran Rekayasa Perangkat Lunak (Terstruktur dan Berorientasi Objek). Bandung: Modula, 2011. 